\title{
An Overview of Management of Root Fractures
}

\author{
Prithviraj DR, ${ }^{1}$ Bhalla $\mathrm{HK},{ }^{1}$ Vashisht $\mathrm{R},{ }^{1}$ Regish KM,${ }^{2}$ Suresh $\mathrm{P}^{1}$
}

\author{
${ }^{1}$ Department of Prosthodontics \\ Govt. Dental College and Research Institute \\ Victoria Hospital Campus,
}

Fort, Bangalore 560002, India

${ }^{2}$ Coorg Institute of Dental Sciences

Virajpet, Coorg, India

\section{Corresponding Author}

D.R. Prithviraj

Department of Prosthodontics

Govt. Dental College and Research Institute

Victoria Hospital Campus,

Fort, Bangalore 560002, India

E-mail: prithvidr@yahoo.com

\begin{abstract}
Crown or root fractures are the most commonly encountered emergencies in the dental clinic. Root fractures occur in fewer than eight percent of the traumatic injuries to permanent teeth. They are broadly classified as horizontal and vertical root fractures. Correct diagnosis of root fractures is essential to ensure a proper treatment plan and hence, the best possible prognosis. Indication of the type of treatment to be used depends primarily on the level of the fracture line. Therefore, a clinician must also have a thorough knowledge of the various treatment approaches to devise a treatment plan accordingly. Various treatment strategies have been proposed, each with their own advantages and disadvantages. Hence, this literature review presents an overview of the various types of root fractures and their management.
\end{abstract}

\section{KEYWORDS}

Horizontal root fractures, root fractures, splinting, traumatic injuries, vertical root fractures.

\section{Citation}

Prithviraj, Bhalla HK, Vashisht R, Regish KM, Suresh P. An Overview of Management of Root Fractures. Kathmandu Univ Med J 2014;47(3):222-30.

\section{INTRODUCTION}

Trauma to the teeth can lead to a wide range of injuries, varying in severity from enamel fractures to avulsions. While crown fractures occur most frequently in the permanent dentition, root fractures account for $0.5-7 \%$ of trauma that occur in the permanent dentition. ${ }^{1} \mathrm{~A}$ radicular fracture involves cementum, dentin and pulp and can be located in either the radicular apparatus (root fracture) or extend onto the coronal portion of the tooth (coronal-root fracture). The maxillary central incisors are most commonly involved because of their anterior position and protrusion caused by the eruptive process, making up $80 \%$ of the cases. ${ }^{2}$ The most affected age range is 3-4 years for primary teeth and 11-20 years for permanent teeth. ${ }^{3}$ Root fractures are uncommon in teeth with incomplete root development and those in various stages of eruption because of resilience of the alveolar bone. ${ }^{4} \mathrm{~A}$ traumatic injury in a deciduous tooth or in one with an incompletely formed root with less periodontal support will most likely result in a luxation or avulsion injury rather than a root fracture. ${ }^{5}$

Etiology of root fractures can be classified into two groups as: Group 1 comprising of fractures occurring in none endodontically treated teeth and Group 2 as fractures occurring in endodontically treated teeth. Group 1 fractures are rare and occur from accidental or occlusal trauma. Group 2 fractures are more common and are due to varying causes, such as excessive condensation forces during canal filling, accidents associated with post preparations, corrosion of posts and accidental or occlusal trauma. ${ }^{6}$

Root fractures can be classified according to the direction in which they occur as: horizontal or vertical. Horizontal root fractures can be further classified based on:

1) The number of fractures lines (simple or multiple) 
2) The location of the fracture line (cervical, middle, or apical) $)^{7}$

3) The position of the coronal segment (displaced and not displaced)

4) The extent of the fracture (partial and total)

Similarly, vertical root fractures can be classified based on:

1) The separation of the root fragments (complete or incomplete)

2) The relative position of the fracture to the alveolar crest (intraosseous and supraosseous).

Diagnosis of root fractures is very important because the treatment plan will be influenced by the teeth which have sustained root fractures. In order to diagnose root fractures, detailed clinical and radiographic examinations are required. When performing the clinical examination, the tooth color must be inspected, and vitality, percussion and mobility tests performed. Other clinical tests, including transillumination, bite test, dye test, and surgical exploration, are also valuable in the diagnosis of vertical root fracture. ${ }^{8}$ Radiographs are used to confirm the diagnosis and may reveal the existence of a fracture line, separated root fragments, space beside a root filling, double images of external root surfaces, bone destruction, wide periodontal ligaments, and radiolucent halos mimicking periodontal disease. ${ }^{9}$ Emerging imaging modalities include cone-beam computed tomography ( $\mathrm{CBCT}$ ) which provides valuable three-dimensional information and optical coherence tomography (OCT) which uses infrared light waves and hence is a non destructive imaging method. ${ }^{10,11}$

The location of the root fracture and the status of the dental pulp determine the type of treatment. ${ }^{12}$ Treatment is usually directed at repositioning and stabilizing the tooth (if necessary) in its correct position and monitoring the tooth for an extended period for pulpal vitality..$^{13}$ Although the outcome of treatment of a root fracture is generally favourable (60-80\% cases), complications such as pulpal necrosis, radicular resorption and pulpal canal obliteration can arise. ${ }^{14}$

For a successful outcome, it is imperative to arrive at an appropriate diagnosis and design a treatment plan accordingly as soon as possible. Diagnosing root fractures and their management is critical not only for any particular speciality but for all the specialities of dentistry. Hence, the aim of this article is to present an overview of various types of root fractures and their management.

\section{HORIZONTAL ROOT FRACTURES}

Horizontal root fractures are characterized by rupture of hard structures of the root, affecting dentin and cementum, separating the tooth into an apical segment, which usually is not displaced, and a coronal segment, which is often displaced. ${ }^{15,16}$ As with most traumatic dental injuries, horizontal root fractures occur more often in the maxillary central incisors of male patients. ${ }^{17}$ They mainly occur in fully erupted teeth with complete root formation and are divided into apical, middle and cervical fractures depending on the location of the fracture line. ${ }^{18-20}$ Caliskan and Pehlivan, in an assessment of 56 root fractures, showed that fracture of the middle third was the commonest, equivalent to $57 \%$ of the cases, followed by fracture of the apical (34\%) and cervical (9\%) thirds. ${ }^{20}$

Clinical management of a horizontal root fracture depends on different variables, such as age of the patient, mobility of the coronal fragment, location of the root fracture, and stage of root formation. ${ }^{21}$ Treatment is usually directed at repositioning and stabilizing the coronal fragment in its correct position and monitoring the tooth for an extended period for pulp vitality. However, assessment of pulpal vitality may be difficult in this situation. Feiglin noted that it may take several months to determine the actual state of vitality. Vitality testing is not indicative of the true pulp status because the nerve supply is damaged and nonfunctional, but the blood supply remains intact. ${ }^{22}$

\section{APICAL THIRD ROOT FRACTURES}

Apical fractures are those occurring in the apical segment of the root. Apical fractures may rarely be diagnosed unless a radiograph is taken since the mobility of the coronal segment is nearly normal. ${ }^{23}$ When a root fractures horizontally, the coronal segment is displaced to a varying degree, but generally the apical segment is not displaced. Because the apical pulpal circulation is not disrupted, there is an extremely rare occurrence of pulp necrosis in the apical segment. Pulp necrosis of the coronal segment displacement occurs in about $25 \%$ of cases. ${ }^{24,25}$

Chances of pulp necrosis are relatively low after an apical third root fracture. As the fracture is below the alveolar crest and no oral contamination occurs, the pulp tissue survives and repairs the fracture with calcified tissue or the periodontal ligament with or without bone may invade the fracture site. ${ }^{19,26}$ Therefore, a watch and observe policy has been advocated as most cases with fracture at the apical third do not even require retention via splinting. ${ }^{16}$ Spontaneous healing of apical fractures has been reported in many cases. Oztan et al have presented two case reports to describe well healed untreated horizontal root fractures of the maxillary right central incisors. Teeth were asymptomatic and tested vital to electric pulp tests. ${ }^{27}$

If required, conservative treatment of such teeth with rigid stabilization and reduction should be done. This procedure is successful in around $80 \%$ of cases especially in the middle and apical third fractures. ${ }^{28}$ Saroglu et al have described treatment for horizontal root fractures located in the apical third of the roots of the teeth 11 and 21 . After administration of local anesthesia, the teeth were gently repositioned by finger pressure and splinted. After 
4 months, the splint was removed. There was no abnormal mobility in the root fractured teeth and all of the teeth gave positive response to the vitality tests and there was no sign of periapical pathology in the radiograph. After 6 years, the teeth were of normal color and mobility. Complete pulp canal obliterations were observed without any sign of pathology. The fracture lines were healed with calcified tissue. $^{14}$

\section{MIDDLE THIRD ROOT FRACTURES}

The traditional treatment modality for middle third root fractures has been repositioning of the coronal fragment and immobilization through fixation to the neighbouring teeth by means of a semi-rigid or rigid splint (e.g. orthodontic wire/composite resin splint, acid-etch/ resin splint) and maintaining the splint for 2-3 months. ${ }^{29}$ Titanium trauma splints have also been advocated which are $0.2 \mathrm{~mm}$ thick rhomboid mesh structures of titanium that can be easily adapted and stabilized on the teeth. They require less application time, are easy to remove and clean and have been considered to be more comfortable. ${ }^{30}$ However, spontaneous healing of these fractures has also been shown in few cases. $^{5}$

The treatment options may be categorized as follows:

\section{1) Repositioning the fractured segment and splinting}

Marco et al reported a case of horizontal fracture in the middle third of the left upper central incisor with a diastasis of $0.1 \mathrm{~mm}$. Based on the clinical aspects that showed pulp with cold-induced sensibility, absence of dental mobility or periapical changes and non-discolored crown, a rigid splinting was performed with an orthodontic wire bonded to the labial surfaces of the maxillary anterior teeth using composite resin. After 45 days of observation, the clinical findings remained unaltered and the rigid fixation was removed. After 4 years of clinical follow-up, it was verified that there were no signs or symptoms associated with the previously fractured tooth. Radiographically, they observed healthy pulp tissue, periodontal structure maintenance and complete healing of the fractured root with fragments in close contact. ${ }^{31}$

The Clinical-radiographic control to assess loss of vitality must continue for 1 month to 1 year, because in this period, there is greater possibility for the occurrence of pulp necrosis. $^{32}$ In $20-44 \%$ of the horizontal root fracture cases, however, the pulp becomes necrotic and this necessitates endodontic treatment to be carried out. ${ }^{29}$ The decision for endodontic treatment may be taken after 3 months of follow-up if the tooth still fails to respond to electrometric or thermal pulp testing and if radiographs show radiolucency next to the fracture line. ${ }^{33}$ Therefore the second treatment option can be,

2) Disinfection and obturation of the coronal segment only If pulp necrosis develops, the apical fragment remains vital in approximately $99 \%$ of cases, while the pulp tissue on the cervical fragment can develop necrosis with consequent formation of granulation tissue between the fragments, ${ }^{4}$ so endodontic treatment is performed only in the coronal segment. An apexification procedure of this segment should be performed before obturation of the root canal. ${ }^{19}$ This technique involves the repeated placement of calcium hydroxide over a period of 6-24 months until a calcific barrier is formed at the fracture line. Disinfection of coronal segment with calcium hydroxide followed by obturation with gutta-percha was found to be the superior technique for the treatment of necrotic teeth fractured in the middle or apical part of the root. ${ }^{34}$ The main drawbacks of this procedure include a need for multiple scheduled visits, susceptibility of treated canals to reinfection as they are restored with temporary fillings, and susceptibility of treated roots to fracture in immature teeth, because root resistance reduces after a long-term contact between calcium hydroxide and root dentin. For these reasons, the use of MTA (mineral trioxide aggregate) in teeth with necrotic pulps and open apices has been recommended. ${ }^{35}$ Because the apical part of the coronal fragment resembles teeth with open apices, MTA can be used for optimal closure of the wound area. In addition, MTA is a biocompatible material that adapts very precisely to the dentinal walls thus providing the hydraulic seal. ${ }^{36,37}$

Kusgoz et al have presented case reports describing the treatment and follow-up of 3 maxillary central incisors with horizontal root fractures treated with MTA as apical plug. All of the above three cases had horizontal root fracture at the mid root level with a diastasis of approximately $1 \mathrm{~mm}$. The coronal fragment was filled with MTA as an apical plug. Radiographs showed healing between the root fragments in each case. Periapical radiolucency had decreased in the fracture areas. ${ }^{38}$

3) The third category of cases may be - of complete pulp necrosis, when endodontic treatment should be performed in both the apical and the coronal fragments. ${ }^{39}$

4) In addition to both the coronal and apical fragments being non-vital, if the fragments are separated and misaligned too, fourth treatment option should be considered that is the-surgical removal of the apical portion. ${ }^{39}$

Marco et al presented a case with a history of trauma to the maxillary anterior region 40 days ago. During radiographic examination, a horizontal root fracture on the middle-third of the left maxillary central incisor was identified. A rigid fixation with orthodontic wire bonded to the vestibular surfaces of the maxillary anterior teeth using composite resin was carried out. Necroses of both cervical and apical fragments of the central incisor were observed. Thus, endodontic treatment of the cervical fragment was performed followed by surgical removal of the apical fragment. Thereafter, the cervical fragment was endodontically instrumented and carefully obturated, without overfilling. After 3 months, the rigid fixation was 
removed. After 5 years of treatment, the patient presented full bone healing on the surgical region, and periodontal structures were visibly healthy. ${ }^{31}$

\section{5) Intraradicular splinting}

Intraradicular splinting of teeth fractured horizontally at the middle root segment has been suggested as an alternative treatment technique. Intraradicular splinting is indicated in cases in which the fracture line is in the middle or coronal segment. The technique involves connecting the tooth fragments through the root canal using a metal pin together with a root canal sealer which may correct the mobility of the coronal segment and the periodontal tissue around the fracture site may heal. ${ }^{40}$ Kroncke reported that fractures of the middle root segment cause the loss of the tooth over time because of pulp necrosis and mobility, and intraradicular splinting is a proven technique for treating such cases. Steel pins, titanium endodontic implants, prefabricated titanium dowels and posts, and ceramic, silver, or alloy cast dowels and posts have been used for intraradicular splinting. ${ }^{41}$

Kocak et al have described this treatment option for upper right central incisor that was occlusally displaced and had a horizontal fracture in middle third that displaced the segments apart. Following local infiltrative anesthetics, the coronal fragment was repositioned. As a result of clinical signs of pulpal necrosis, both the coronal and the apical root fragments were endodontically treated and obturated at single visit, and the fragments were stabilized internally through insertion of a stainless-steel endodontic file into the root canal. Just before completion of the root canal filling, a size 40 Hedstrom file was inserted into the root canal with clockwise winding motion to further reduce the fracture and also to achieve anchorage from the apical fragment for the coronal fragment. The file was separated intentionally, approximately at the cervical level. Four-year follow-up examination revealed satisfactory clinical and radiographic findings with hard tissue repair of the fracture line. This technique can be a quick remedy for patients with root-fractured tooth, especially for those who cannot make a second visit to the dental clinic. ${ }^{29}$

6) Removal of the apical segment and stabilization of the coronal segment with endodontic implants.

Feldman and Feldman, advocated the use of endodontic stabilizers as a means of stabilizing and retaining seemingly nonretainable teeth. ${ }^{42}$ The basis for an endodontic stabilizer is the use of chrome cobalt pin as the implant material. This alloy is composed of $65 \%$ cobalt, $30 \%$ chromium, and $5 \%$ molybdenum. Bernier and Canby have verified nonelectrolytic, inert properties as well as excellent tissue tolerance to the material. The endodontic stabilizer increases the root anchorage in the bone by the extension of the artificial material beyond the limit of the alveolar socket within the limits of the alveolar bone and thus helps in stabilizing the teeth with compromised alveolar support. Mittal et al have described this treatment option for mid root fracture of 11 that had greater amount of external root resorption. As both the fragments were displaced wide apart, it was decided to extract the apical fragment surgically and place the endodontic implant. An endodontic stabilizer was used in conjunction with surgical intervention and bone grafting. This case was considered successful on the basis of clinical and radiographic findings. ${ }^{43}$

\section{CERVICAL THIRD ROOT FRACTURES}

Though relatively uncommon, ${ }^{44}$ intraalveolar root fractures in the cervical area of a tooth, especially in the anterior region, present many clinical challenges. The prognosis of root fractures in the cervical one third is considered to be poor due to a short mobile coronal fragment, with less probability of healing with hard tissue, and possible bacterial contamination of the root canal from the gingival crevice. In the cervical third healing depends on the proximity of the root fracture to the gingival sulcus. ${ }^{45}$ However, recent studies reported that no relationship could be demonstrated between the frequency of pulp necrosis and position of the fracture line, and therefore extraction of teeth has not been supported. ${ }^{46}$

It has also been shown that cervical fractures may heal and a conservative approach, including a relatively long splinting period, has been recommended. ${ }^{45} \mathrm{~A}$ longer splinting period of 6 months to 1 year is required because of the mobility of the coronal segment. ${ }^{39}$

Terata et al, in their case report, have described a conservative treatment for root fracture located very close to the gingiva. The treatment of root fracture was by repositioning and fixation. A 7-years follow-up showed healing with calcified tissue and pulp canal obliteration. ${ }^{46}$

If the fracture line is coronal and bacterial contamination is present through the gingival crest, the pulp tissue becomes necrotic. ${ }^{29}$ Healing does not take place if an interaction between the fracture line and the oral environment exists, because of bacterial contamination from bacteria in the sulcus ${ }^{47}$ In such cases, endodontic treatment is necessary. In a case report by Rabie et al, the treatment of a maxillary right central incisor with an intra-alveolar horizontal root fracture in the coronal one-third of the root is described. Repositioning and immobilization of the coronal fragment were carried out. After 2 months, the clinical examination revealed the pulp in the coronal fragment to be necrotic. Radiographically, a small periapical radiolucency was seen. Endodontic therapy was initiated and the pulp in the apical fragment proved to be necrotic as well. Instrumentation of the root canal through the fracture line and long-term calcium hydroxide treatment were carried out. One year later the radiograph indicated repair of the fracture with hard tissue. The tooth was then obturated with guttapercha and restored with an acid-etch resin technique. At the 12-month follow-up examination, the tooth was functionally and esthetically normal. Radiographically, the 
fracture line was not discernible and repair of the apical periodontitis had taken place. ${ }^{48}$

If the fracture line extends below the level of the alveolar bone crest and the remaining root structure is long enough to support the subsequently applied restoration, only the fractured portion is extracted and root canal therapy is performed. In the above case, gingivectomy, surgical or orthodontic extrusion of the apical fragment is necessary to convert the subgingival fracture to a supragingival one in order to restore the fracture either with the original fragment or composite resins. ${ }^{49}$ Failure to place a definitive margin of the restoration on tooth structure may violate the biological width, leading to restorative failure. The possible treatment options available to elevate the fracture line above the epithelial attachment are surgical crown lengthening, surgical extrusion or orthodontic extrusion (using a fixed or removable appliance). ${ }^{50}$

\section{1) Crown lengthening}

Periodontal surgery recommended for crown lengthening includes gingivectomy, apically positioned flap or ostectomy-osteoplasty. These procedures may sacrifice supporting bone on several healthy teeth, create poor crown-root ratio and cause excessive tooth mobility. ${ }^{51}$

\section{2) Surgical extrusion}

It is carried out for patients who are treated on an emergency basis, having severe luxation of the fractured root. In this technique, the tooth is carefully extruded to the required position by marginal luxation and stabilized by interdental suturing and surgical dressing. If the fracture line is more apical on the labial side, a rotation of $180^{\circ}$ is given before fixation. With this method the bone support around the root is usually lost. ${ }^{52}$

\section{3) Orthodontic extrusion}

A highly satisfactory alternative to the surgical approach is the controlled orthodontic extrusion of the fractured root. The method is also called forced eruption, orthodontic eruption, vertical extrusion or assisted eruption. First reported by Heithersay and Ingber, controlled orthodontic extrusion is considered the easiest orthodontic tooth movement that can produce excellent results with a good prognosis and a low risk of relapse..$^{53}$

Forced eruption is indicated primarily in the anterior region of the dentition where esthetics is a major concern. Posteriorly in the dental arch, surgical crown lengthening may be more appropriate because flared molar roots may present proximity problems if extruded, and esthetics is less important. Tipping and unfavourable axial tooth position may also preclude extrusion. ${ }^{54}$ The vertical tooth movement can be obtained with removable or fixed orthodontic appliances, the former using mostly elastic bands or magnets, and fixed appliances and many modifications thereof referred to when the tooth is extruded mostly applying a fabricated resin based crown with a bonded orthodontic bracket. ${ }^{53}$ The lingual orthodontic technique was also proposed for exposing sound tooth structures with excellent aesthetic results. ${ }^{55}$

Harun et al have described a case report on the management of a cervical root fracture using orthodontic extrusion and a final restoration with the patient's fractured natural crown. Radiographs revealed an oblique fracture extending to approximately one-third of the entire root length. The coronal fragment was extracted because of excessive mobility and stored in sterile saline at $4^{\circ} \mathrm{C}$ until final restorative procedures. After pulp extirpation, the root was filled temporarily with calcium hydroxide and orthodontic extrusion was initiated. The remaining root portion was elevated above the epithelial attachment and a successful coronal restoration was made using the natural crown of the traumatized tooth. ${ }^{56}$

Using the original fragment to restore crown and crownroot fractures presents some advantages over composite restorations:

1. The technique is generally faster, economical and less complicated;

2. More aesthetic restoration could be attained particularly by conserving the original translucency and contours;

3. The restored tooth is more resistant to stain and abrasion than a resin restoration. ${ }^{56}$

A modification of the forced eruption technique has also been presented. The fractured fragment of a patient's crown was bonded to the adjacent teeth and used as anchorage, permitting the root extrusion while offering acceptable aesthetics. The bonded crown does not impede the eruption of the root so that the frequent occlusal adjustment of other methods was not required. An elastic band attached to the head of the post cemented temporarily into the canal was used for extrusion of the root. After root extrusion, porcelain fused to metal crown was given as the final restoration. The final result was acceptable and a low cost alternative to common techniques. ${ }^{53}$

When using a conventional fixed appliance, elastic traction may induce a more buccal force component during the extrusion, as brackets and wires of the anchoring teeth are positioned more buccally than the root. This results in buccal tipping or rotation during extrusion. Arhun et al suggested that the use of endodontic posts may be useful in exerting vertical forces to the root for extrusion without buccal tipping. Small holes were prepared at the heads of the prefabricated metal posts into which orthodontic wires would be attached. Orthodontic forced eruption was achieved using endodontic posts and restored with porcelain fused to metal crowns-leading to successful restoration of the traumatised teeth. ${ }^{57}$

Vital root submergence of horizontally fractured teeth with an open apex can be considered as a possible treatment option. When the root fragment is too short to support a 
coronal restoration, it may be submerged in situ to preserve alveolar bone until the patient is old enough to have an implant or fixed partial denture. The coronal segment of the tooth is removed and the gingival tissue is sutured over the exposed root stump to achieve primary closure. The exposed pulp may not be covered with a medicament or restorative material prior to closure. Johnson et al have described the treatment of a tooth with a cervical third horizontal root fracture by vital root submergence and subsequent conventional root canal therapy and prosthetic restoration. ${ }^{58}$ The various treatment options to manage horizontal root fractures have been summarized in Figure 1.

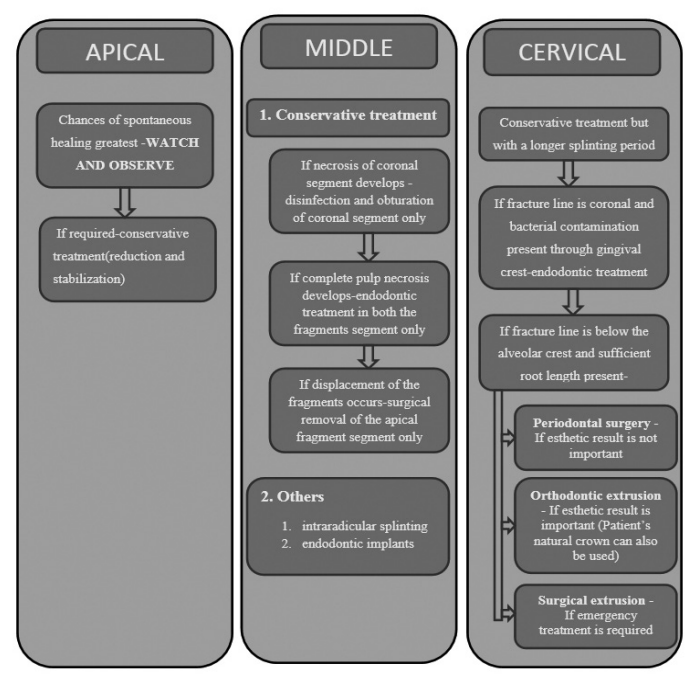

Figure 1. Management of Horizontal Fractures.

\section{VERTICAL ROOT FRACTURES}

Vertical root fractures, or VRFs, usually are characterized by an incomplete or complete fracture line that extends through the long axis of the root towards the apex. ${ }^{59}$

Vertical root fracture represents 2 to $5 \%$ of crown/root fractures, most frequently they occur in endodontically treated teeth, and are mainly iatrogenic, although occurrence in non-treated teeth has also been described. ${ }^{60}$ In molar teeth, the fracture is most commonly bucco-lingual in orientation in individual roots. Mesio-distal fractures are less common. In anterior teeth, the fractures are most commonly in a bucco-lingual direction. The vertical root fracture may involve the whole length of the root or only a section of it, and may involve only one or both sides of the root. ${ }^{61}$ Complete or incomplete VRFs constitute an ongoing problem in dentistry because they are difficult to be diagnosed in the early stages. In most cases, tooth extraction is the only reasonable treatment when the VRF is finally diagnosed. ${ }^{62}$ But other treatment options have also been put forward.

Treatment of vertically fractured teeth is difficult and is dependent on the tooth type as well as on the extent, duration and location of the fracture. The majority of vertical fractures involve the gingival sulcus and result in destruction of the periodontium to the apical extent of the fracture, due to ingress of bacteria and other irritants, resulting in alveolar bone loss in almost all teeth. Repair of the periodontium and the bone cannot occur in the presence of bacterial infection. The aim of treatment is therefore to eliminate the fracture or the leakage of bacteria along the fracture plane. Multirooted teeth can often be successfully treated by resecting the fractured root, either by root amputation or hemisection. Prognosis for posterior teeth is good, provided the fracture can be removed in its entirety. Studies of root resected teeth have reported five year retention rates of 94 percent and ten year retention rates of 68 per cent. A series of treatment options for posterior teeth involving hemisection and root amputation has been described in the literature. ${ }^{61}$

The preservation of maxillary molars with vertical fractures down to the root is particularly difficult. Takatsu et al have described a method to treat such vertical root fractures. They described the treatment of a maxillary second molar exhibiting a complete vertical crown-root fracture. The buccal and palatal segments were widely separated by as much as $2 \mathrm{~mm}$ and were immobile. To restore this tooth, it was essential to bring the segments into close apposition. Minor orthodontic movement was used in combination with the wire-binding repositioning technique at the initial stages of treatment. They used orthodontic elastics to join the buccal and palatal segments of vertical fractured root, which were then sealed with a photo-cured resin liner so as to allow the tooth for root canal treatment and later restoration with a cast crown. ${ }^{63} \mathrm{~A}$ slightly different method based on the wire repositioning technique was given by Yokoyama et al by repositioning and fixing with wires through holes prepared on the bucco-palatal surfaces, they succeeded in achieving a good clinical result. Orthodontic wire was inserted through the holes and tightened to prevent further displacement of the segments. The wired holes and the prepared cavities were filled with resin and an abutment preparation for a full crown was carried out without removing the wires. ${ }^{64}$

In general, the prognosis for single rooted teeth is poor and extraction is often the treatment of choice. Clinicians have tried to retain anterior teeth by either removing the fractured segment or bonding the root using biocompatible materials like cyanoacrylate, glass ionomer cement (GIC), and composite resin. ${ }^{65-67}$ An in vitro study assessing the resistance to fracture of root segments bonded with glass ionomer cement, composite resin and cyanoacrylate concluded that the bond strengths of composite resin and cyanoacrylate were superior to GIC. ${ }^{68}$ Funato et al have described the non surgical treatment of an incomplete vertical root fracture by cementation with adhesive resin intentionally after endodontic treatment. ${ }^{69}$ Calcium hydroxide has been used to promote tissue repair and resolve osseous defects before restoring the roots with GIC. Teeth treated with calcium hydroxide ,then 'reinforced' with glass ionomer cement, have shown healing at six-month 
follow up appointments. ${ }^{70}$ Studies using an expanded polytetrafluoroethylene Gore-Tex membrane to establish a new periodontal attachment after the fragments have been bonded with GIC have reported differing results, six teeth failed in a twelve month period. ${ }^{67}$ Only one study has reported success with this method of treatment. Trope et al have described the treatment of a vertically fractured upper left second molar. The two fragments were extracted separately. The periodontal ligament was protected from damage extraorally by soaking it with Hanks balanced salt solution. The two segments were bonded with the use of biocompatible glass ionomer bone cement and replanted in conjunction with an expanded polytetrafluoroethylene (gore-tex) membrane. After 1 year follow-up, the tooth was functioning normally and was clinically and radiographically within normal limits. ${ }^{71}$

The use of lasers for bonding the two separated segments has also been suggested but an in-vitro study proved carbon dioxide and $\mathrm{Nd}$ :YAG lasers to be ineffective for fusing fractured tooth roots, because results revealed heat-induced fissures and cracks, as well as breakdown and separation of cementum from the underlying dentin. ${ }^{72}$

Root extrusion and/or intentional replantation are also possible treatment options. In the latter case,the fractured segments are atraumatically extracted, bonded and are then reimplanted. Although the clinical symptoms of a vertically fractured root are improved by intentional replantation using adhesive resin cement, the narrow periodontal pockets along the fracture line usually remain. In the treatment of periodontally weakened teeth with extensive alveolar bone loss and deep periodontal pockets extending to the apex at one or two root surfaces and a healthy periodontal ligament on other surfaces, intentional replantation is reported to improve the periodontal pockets with rotation. Rotation is preferred in order to avoid contact with the area where the periodontal ligament was lost and the area where the bone was lost. Rather the denuded surfaces now contact healthy surfaces of periodontal ligament or bone which might inhibit the development of periodontal pockets along the fracture line. ${ }^{73}$ Therefore, root extrusion or intentional re-implantation with $180^{\circ}$ rotation and with splinting has also been tried as a means of treating complete vertical root fractures. It is composed of two steps. First the fractured tooth is intentionally extracted atraumatically and then the separated fragments are bonded with an adhesive resin cement.The restored tooth is replanted by rotating approximately $180^{\circ}$ into the original socket and fixing with an orthodontic wire. Kawai et al have described the successful treatment of two cases with vertical fractures using the above method. ${ }^{65}$

Though the majority of root fractures are complete, fracture of only one side may occur. In these instances, complete removal of the fracture has been proposed. It has been suggested that in instances where the gingival sulcus is intact, the root can be sectioned, maintaining a long bevel and eliminating the entire fractured segment. A fibreoptic light source or the uses of die are valuable aids in assessing the fracture lines. ${ }^{57}$

If none of the above options seem to be feasible, complete removal of the fractured segments followed by immediate implantation can also be considered. In addition, Leubke has proposed four basic categories of treatment as given in Figure $2 .{ }^{74}$

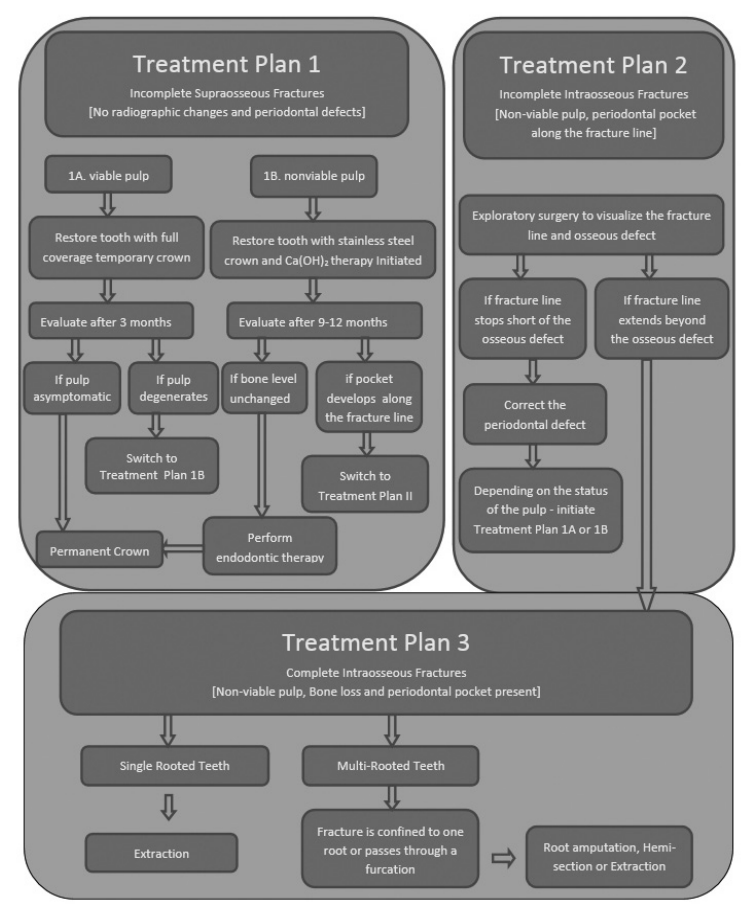

Figure 2. Management of Vertical Fractures.

\section{CONCLUSION}

Root fractures are uncommon lesions accounting for $0.5-7 \%$ of traumas that occur in the permanent dentition. They involve the tooth's supportive tissue, dental pulp and mineralized structures, affecting predominantly the middlethird of upper incisors of male patients during the second decade of life. Indeed, root fractures can be associated with alveolar bone fractures. The clinician should make a careful diagnosis of each tooth and be prepared for different treatment approaches to preserve the injured teeth and it is suggested that the approach adopted for any patient may be the conservative management of root fragments following trauma. However, it appears that the diagnosis of vertical root fracture presents a challenge in clinical dentistry. By carefully continuing the patient's history and symptoms as well as radiographic and clinical findings, it will often be possible to verify the presence of a fracture and adopt a treatment plan. Continuous follow up of the patients' oral hygiene and radiographic controls for the detection of early signs of any pathology are required in all of the trauma cases.The diagnosis and management of fractured roots will affect the total treatment of a patient and hence the quality of life. 


\section{REFERENCES}

1. Poi WR, Manfrin TM, Holland R, Sonoda CK. Repair characteristics of horizontal root fracture: a case report. DentTraumatol 2002 Apr;18:98-102

2. Majorana A, Pasini S, Bardellini E, Keller E. Clinical and epidemiological study of traumatic root fractures. Dent Traumatol 2002 Apr;18:77-80.

3. Cavalleri G, Zerman N. Traumatic crown fractures in permanent incisors with immature roots: a follow-up study. Endod Dent Traumatol 1995;11:294-6.

4. Andreasen JO, Hjorting-Hansen E. Intra-alveolar root fractures: radiographic and histologic study of 50 cases. J Oral Surg 1967; 25:414-26.

5. Cobankara FK, Ungor M. Spontaneously healed horizontal root fracture in maxillary first premolar: report of a case. Dent Traumatol 2007 Apr;23:120-2.

6. Borelli P, Alibrandi P. Unusual horizontal and vertical root fractures of maxillary molars: an 11-year follow-up. J Endod 1999 Feb;25:136-9.

7. Andreasen JO, Andreasen FM. Textbook and color atlas of traumatic injuries to the teeth. Copenhagen, Denmark: Munksgaard; 1994. p. 750.

8. Barkhordar RA, Kempler D, Knapp J. Mesiodistal root fracture:Three case reports. Oral Surg Oral Med Oral Pathol. 1988 Mar;65:343- 9.

9. Mullally $\mathrm{BH}$, Ahmed M. Periodontal signs and symptoms associated with vertical root fracture. Dent Update 2000; 27: 356-360

10. Krastl G, Filippi A, Zitzmann NU, Walter C, Weiger R. Current aspects of restoring traumatically fractured teeth. EurJ Esthet Dent 2011 Summer;6:124-41.

11. Shemesh H, van Soest G, Wu MK, Wesselink PR. Diagnosis of vertical root fractures with optical coherence tomography. J Endod. 2008 Jun;34:739-42.

12. Gomes AP, de Araujo EA, Gonçalves SE, Kraft R. Treatment of traumatized permanent incisors with crown and root fractures: a case report. Dent Traumatol 2001 Oct;17:236-9.

13. Chala S, Sakout M, Abdallaoui F Repair of untreated horizontal root fractures: two case reports Dent Traumatol 2009 Aug;25:457-9. Epub 2009 Jun 1

14. Saroğlu I, Sönmez H. Horizontal root fracture followed for 6 years. Dent Traumatol 2008 Feb;24:117-9

15. Andreasen JO, Andreasen FM. Texto e atlas colorido detraumatismo dental. Porto Alegre: Artmed Editora; 2001.770 p.

16. Soares IJ, Goldberg F. Endodontia: te'cnica e fundamentos. Porto Alegre: Artes Médicas Sul. 2001; 376 p

17. Andreasen JO. Etiology and pathogenesis of traumatic dental injuries. A clinical study of 1,298 cases. Scand J Dent Res 1970;78:329-42.

18. Andreasen JO, Andreasen FM. Textbook and Color Atlas of Traumatic Injuries to the Teeth, 3rd edn. Copenhagen: Munksgaard; 1994. p. 279-314.

19. Hovland EJ. Horizontal root fractures: treatment repair. Dent Clin North Am 1992;36:509-25.

20. Calıskan MK, Pehlivan Y. Prognosis of root-fractured permanent incisors. Endod Dent Traumatol 1996;12:129-36.

21. Andreasen JO, Andreasen FM, Mejare I, Cvek M. Healing of 400 intra-alveolar root fractures. 2. Effect of treatment factors such as treatment delay, repositioning, splinting type and period and antibiotics. Dent Traumatol 2004;20:203-11.

22. Andreasen JO. Etiology and pathogenesis of traumatic dental injuries. A clinical study of 1,298 cases. Scand J Dent Res 1970;78:329-42.

23. Andreasen JO, Andreasen FM. Texto e atlas colorido detraumatismo dental. Porto Alegre: Artmed Editora. 2001; 770 p.
24. Andreasen FM, Andreasen JO. Resorption and mineralization processes following root fracture of permanent incisors. Endod Dent Traumatol 1988;4:202.

25. Andreasen FM, Andreasen JO, Boyer T. Prognosis of root fractured permanent incisors:prediction of healing modalities. Endod Dent Traumatol 1989;5:11-22.

26. Andreasen FM, Andreasen JO editors. Textbook and color atlas of traumaric injuries to the teeth. Copenhagen: Munksgaard 1993; p. 279-314.

27. Oztan MD, Sonat B. Repair of untreated horizontal root fractures: two case reports. Dent Traumatol 2001 Oct;17:240-3.

28. Ferrari PH, Zaragoza RA, Ferreira LE, Bombana AC. Horizontal root fractures: a case report. Dent Traumatol 2006 Aug;22:215-7.

29. KocakS, CinarS, KocakMM, KayaogluG.Intraradicular splinting with endodontic instrument of horizontal root fracture-case report. Dent Traumatol 2008 Oct;24:578-80.

30. Adatia A, Kenny DJ. Titanium trauma splint:an alternate splinting product. J Cand Dent Assoc 2006; 72: 721-3.

31. Versiani MA, de Sousa CJ, Cruz-Filho AM, Perez DE, Sousa-Neto MD Clinical management and subsequent healing of teeth with horizontal root fractures. Dent Traumatol 2008 Feb;24:136-9.

32. Brandini DA, Poi WR, Panzarini SR, Sonoda CK, de Castro JC, Luvizuto $E R$, Leal CR Integrated treatment to resolve a horizontal root fracture. Dent Traumatol 2009Apr;25:e16-20.

33. Flores MT, Andersson L, Andreasen JO, Bakland LK, Malmgren $B$, Barnett $F$ et al. Guidelines for the management of traumatic dental injuries. I. Fractures and luxations of permanent teeth. Dent Traumatol 2007;23:66-71.

34. Cvek M, Mejare I, Andreasen JO. Conservative endodontic treatment of teeth fractured in the middle or apical part of the root. Dent Traumatol 2004;20:261-9.

35. Roig $M$, Espona J, Mercadé $M$, Duran-Sindreu $F$ Horizontal root fracture treated with MTA, a case report with a 10-year follow-up. Dent Traumatol 2011 Dec;27:460-3.

36. Giuliani V, Baccetti T, Pace R, Pagavino G. The use of MTA in teeth with necrotic pulps and open apices. Dent Traumatol 2002;18:217-21.

37. Gondim E, Zaia AA, Gomes BPFA, Ferraz CCR, Teixeira FB,SouzaFilho FJ. Investigation of the marginal adaptation of rootend filling materials in root-end cavities prepared with ultrasonic tips. Int Endod J 2003;36:491-9.

38. Kusgoz A, Yildirim T, Tanriver M, Yesilyurt C. Treatment of horizontal root fractures using MTA as apical plug: report of 3 cases. Oral Surg Oral Med Oral Pathol Oral Radiol Endod 2009 May;107:e68-72.

39. Westphalen VP, de Sousa MH, da Silva Neto UX, Fariniuk LF, Carneiro $E$. Management of horizontal root-fractured teeth: report of three cases. Dent Traumatol 2008 Aug;24:e11-5. Epub 2008 Jun 28.

40. Subay RK, Sübay MO, Yilmaz B, Kayataş M. Intraradicular splinting of a horizontally fractured central incisor: a case report. Dent Traumatol 2008 Dec;24:680-4.

41. KronckeVA.ZurProblematikderendodontalenSchienunugfrakturierter Zahnwurzeln. Dtsch Zahnarztl Z 1969;24:49-53.

42. Strock $A E$, Strock MS. Method of reinforcing pulpless anterior teethpreliminary report. J Oral Surg 1943;1:252-5

43. Mittal S, Kumar T, Aggarwal V, Bansal R, Kaur D.Endodontic stabilizers for treating mid root fractures. J Interdiscip Dentistry 2011;1:108-10

44. Zachrisson BU, Jacobsenl. Long-term prognosis of 66 permanent anterior teeth with root fracture. Scand J Dent Res 1975 Nov; 83: 345-54.

45. Cvek M, Mejàre I, Andreasen JO. Healing and prognosis of teeth with intra-alveolar fractures involving the cervical part of the root Dent Traumatol. 2002 Apr;18:57-65. 
46. RintaroT, KiyotakaM, MinoruK. Conservative treatment for root fracture located very close to gingiva. Dent Traumatol 2005 Apr;21:111-4.

47. Erdemir A, Ungor M, Erdemir EO. Orthodontic movement of a horizontally fractured tooth: a case report. Dent Traumatol 2005 Jun;21:160-4.

48. Rabie G, Barnett F, Tronstad L Long-term splinting of maxillary incisor with intra-alveolar root fracture. Endod Dent Traumatol 1988 Jun;4:99-103.

49. Turgut MD, Gönül N, Altay N Multiple complicated crown-root fracture of a permanent incisor. Dent Traumatol 2004 Oct;20:288-92.

50. Andreasen FM, Andreasen JO, Cvek M. Root fractures. In: Textbook and color atlas of traumatic injuries to teeth. Andreasen F M, Andreasen J O (eds). Copenhagen: Blackwell Publishing Ltd, 2007:337-371.

51. Shiloah J. Clinical crown lengthening by vertical root movement. J Prosthet Dent. 1981 Jun;45:602-5.

52. Kahnberg KE. Intra-alveolar transplantation.I. A 10-year follow-up of a method for surgical extrusion of root fractured teeth. Swed Dent J 1996; 20: 165-172.

53. Emerich-Poplatek K, Sawicki L, Bodal M, Adamowicz-Klepalska B. Forced eruption after crown/root fracture with a simple and aesthetic method using the fractured crown. Dent Traumatol 2005 Jun;21: $165-9$

54. Johnson GK, Sivers JE Forced eruption in crown-lengthening procedures. J Prosthet Dent 1986 Oct;56:424-7.

55. Baker IM. Esthetic extrusion of a nonrestorable tooth. J Clin Ortho 1990;24:323-5.

56. Canoglu H, Gungor HC, Cehreli ZC. Management of cervical root fracture using orthodontic extrusion and crown reattachment: a case report. Oral Surg Oral Med Oral Pathol Oral Radiol Endod 2007 Sep;104:e46-9.

57. Arhun $\mathrm{N}$,Arman A,Ungor M,Erkut S.A conservative multidisciplinary approach for improved esthetic results with traumatised anterior teeth. Br Dent J 2006 Oct 21;201:509-12

58. Johnson BR, Jensen MR. Treatment of a horizontal root fracture by vital root submergence. Endod Dent Traumatol 1997 Oct;13:248-50.

59. Tamse A, Fuss Z, Lustig J, Kaplavi J. An evaluation of endodontically treated vertically fractured teeth. J Endod 1999 Jul;25:506-8.
60. Gher ME Jr, Dunlap RM, Anderson MH, Kuhl LV. Clinical survey of fractured teeth. J Am Dent Assoc 1987;114:174-7.

61. Moule AJ, Kahler B. Diagnosis and management of teeth with vertical root fractures. Aust Dent J. 1999 Jun;44:75-87.

62. Hegde MN, Hegde ND, Haldar C. Vertical root fractures: Review and case report. J Interdiscip Dentistry 2011;1:101-4.

63. Takatsu T, Sano H, Burrow MF. Treatment and prognosis of a vertically fractured maxillary molar with widely separated segments: a case report. Quintessence Int 1995;26:479-84.

64. Yokoyama K, Matsumoto K, Kinoshita J, Sasaki H, Komori T. Treatment of maxillary molars with vertical fractures. Endod Dent Traumatol 1998 Dec;14:287-9.

65. Kawai K, Masaka N. Vertical root fracture treated by bonding fragments and rotational replantation. Dent Traumatol 2002;18:42-5.

66. Oliet S. Treating vertical root fractures. J Endod 1984;10:391-6.

67. Selden HS. Repair of incomplete vertical root fractures in endodontically treated teeth-in vivo trials. J Endod 1996;22:426-9.

68. Firedman S, Moshonov J, Trope M. Resistance to vertical fracture of roots, previously fractured and bonded with glass ionomer cement, composite resin and cyanoacrylate cement. Endod Dent Traumato 1993 Jun;9:101-5.

69. Funato A, Funato $H$, Matsumoto K. Treatment of a vertical root fracture. Endod Dent Traumatol 1999 Feb;15:46-7.

70. Barkhordar RA. Treatment of vertical root fracture: a case report Quintessence Int 1991 Sep;22:707-9.

71. Trope M, RosenbergES.Multidisciplinary approach to the repair of vertically fractured teeth. J Endod 1992 Sep;18:460-3.

72. Arakawa S, Cobb CM, Rapley JW, Killoy WJ, Spencer P. Treatment of root fracture by $\mathrm{CO} 2$ and $\mathrm{Nd}$ :YAG lasers: an in vitro study. J Endod 1996 Dec;22:662-7.

73. Kudou Y, Kubota M.Replantation with intentional rotation of a complete vertically fractured root usingadhesive resin cement. Dent Traumatol 2003 Apr;19:115-7.

74. Luebke RG. Vertical crown-root fractures in posterior teeth. Dent Clin North Am 1984 Oct;28:883-94. 